УДК 882.-1.09

\title{
С. Лобзова
}

\section{PAНHЕЕ ТВОРЧЕСТВО ГЕОРГИЯ ИВАНОВА: ЛИРИЧЕСКИЙ ЦИКЛ «ОТПЛЫТЬЕ НА О. ЦИТЕРУ»}

Георгий Иванов (1894-1958) - один из самых известных поэтов русского зарубежья, творчество которого, по известным причинам, довольно долго оставалось незамеченным советским литературоведением. Однако в последние десятилетия появляется все больше работ, авторы которых занимаются исследованием поэтики и проблематики наследия замечательного представителя поэзии Серебряного века.

Стихи Иванов начал писать еще в гимназические годы. С 1811 года он уже печатался в журнале «Гаудеамус», в этом же году завел знакомства с Г. Чулковым, И. Северяниным, М. Кузминым, А. Блоком. Последний оставил в своем дневнике следующее воспоминание о беседе с начинающим поэтом: «Уже мог сказать ему (об óvó $\mu v \eta \alpha i \varsigma^{\prime}$ е о Платоне, о стихотворении Тютчева, о надежде) так, что он ушел другой, чем пришел» [4, с. 93]. Получив «поэтическое благословение» от ведущего поэта-символиста, Иванов заявил о себе как мастер верификации, издав на собственные средства первую книгу стихов, озаглавленную в духе популярных в среди представителей модернизма многочисленных стилизаций. Называлась она «Отплытье на о. Цитеру». В сборнике отразилось кратковременное увлечение молодого поэта кубофутуризмом, что нашло выражение как в подзаголовке - «Поэзы», так и в поэтике стихотворений. Книга сразу привлекла внимание критиков, чьи мнения разделились.

Эгофутурист И.В. Игнатьев в рецензии отмечал, что Иванов - «это почти уже нашедший себя поэт-идиллик, поэт-эстет. < .. > У Георгия Иванова жизнь, судьба жизни и индивидуал - единое нерасчлененное целое. Иванов - эстет в жизни и в лирике. Как показывает само название книги, материал, содержащийся в ней, отражает лучи (C) С. Лобзова, 2019

http://dx.doi.org/10.34142/2312-1076.2019.4.94.09 
Эроса. В темных поэзах чувствуете пряный аромат курений Эллады. $<. .>$ Каждая группа поэз хороша по-своему. Нежное, тепличное дарование молодого пииты особенно сильно (выражение это как-то не вяжется с хрупкою музою Иванова), красочно выражено в поэзах “На острове Цитере”, “Вечерние строфы”, “Осенний брат”, “Заря Пасхальная” и “Схима”» [8]. Талант Иванова был признан такими мэтрами поэзии Серебряного века, как В. Брюсов и Н. Гумилев. Отметив подражательность ивановских поэз, в которых явно прослеживалось сходство со стихами Кузмина и Северянина, они подчеркнули безупречность вкуса и высокое мастерство техники стихосложения. В частности, Гумилев в рецензии, помещенной в журнале « «...Первое, что обращает на себя внимание в книге Георгия Иванова, - это стих. Редко у начинающих поэтов он бывает таким утонченным, то стремительным и быстрым, чаще только замедленным, всегда в соответствии с темой» [Цит. по: 3, с. 109].

Однако были критики, которые скептически отреагировали на «сомнительные рифмы» ивановских стихов (Е. Уманец), упрекая поэта в смешении эпох и традиций, отсутствии исторической правды, торжестве поэтической условности и вымысла, которым поэт отдавал предпочтение перед точным воспроизведением жизненных реалий или в простой банальности (В. Лесовой). Можно сказать, что за деревьями эти критики не заметили леса, т.е. просмотрели или не поняли новизну и оригинальность стиля молодого поэта, по сути, пролагавшего новые пути, по которым будет развиваться поэзия XX века - ее условность, игровой характер, диалогизм и вытекающую из него интертекстуальность.

К сожалению, мнение некоторых современников Иванова разделяют некоторые современные ученые, в частности, В. Крейд, обвинивший его в подражательности и примитивности: «О самостоятельности содержания стихов «Отплытья на о. Цитеру» говорить тоже не приходится. Лучшее, что в них есть, так это «... наивно-простодушный вкус...» [11, с. 25]. Полагаем, что все же гораздо более справедлива оценка, данная первому сборнику поэта В. Коровиным, который считал, что ранняя поэзия Иванова 
значительно уступает его стихам, созданным в эмиграции, но если судить объективно и беспристрастно, то можно утверждать, что «первая поэтическая книга не только весьма примечательна, но и по-настоящему хороша» и далее, ученый называет два бесспорных достоинства книги - «безупречность вкуса» и «своебычный авторский голос» [9, с. 595].

Целью данной статьи является анализ особенностей лирической циклизации первой книги Георгия Иванова «Отплытье на о. Цитеру». Если эмигрантским циклам поэта было посвящены работы таких литературоведов как О.Л. Коренькова, О.А. Чехунова и др., то первый цикл был обойден вниманием ученых. Мы попытаемся восполнить этот пробел.

Теоретическими проблемами циклизации занимались такие ученые, как М. Дарвин, Л. Ляпина, В. Сапогов, И. Фоменко и др. Они неоднократно отмечали, что именно для поэтов Серебряного века характерно стремление к объединению стихотворений в циклы. Это было обусловлено, по мнению В.М. Жирмунского, намерением «выйти за пределы узкой композиционной формы краткого и замкнутого в себе лирического стихотворения» [6, с. 115-116]. Многие поэты осознавали эту тенденцию, присущую их эпохе и пытались дать ей теоретическое обоснование. Например, один из ведущих теоретиков и поэтов символизма Андрей Белый пришел к заключению, что «только на основании цикла стихов одного и того же автора медленнее выкристаллизовывается в воспринимающем сознании то общее целое, что можно назвать индивидуальным стилем поэта; и из этого общего целого уже выясняется «зерно» каждого отдельного стихотворения; каждое стихотворение преломляемо всем рядом смежно-лежащих; и весь ряд слагается в целое, не открываемое в каждом стихотворении, взятом порознь» $[2$, c. 550]. Действительно, это очень верное замечание очень точно обосновывает целостность как непременное условие циклизации.

В целом циклизация как литературный феномен продолжает нуждаться в дальнейших исследованиях. Так, остается открытым вопрос о его жанровой или метажанровой природе, 
среди ученых существуют разногласия по поводу того, какие именно содержательные и формальные элементы цикла считать циклообразующими и т.д. Под циклом мы будем понимать «группу произведений, сознательно объединенных автором по жанровому, тематическому, идейному принципу или общностью персонажей» $[10$, c. 398$]$.

Обобщив имеющийся на сегодняшний день теоретический материал, назовем основные циклообразующие признаки: наличие у цикла стихотворений заглавия, общность хронотопа и лирических героев, возможность выделить единый лирический сюжет, сквозные образы, различные переклички между стихотворениями на языковом и тематическом уровнях и т.д.

Как известно, заглавие ивановского сборника отсылает читателя к знаменитым картинам французского художника «галантного века» Антуана Ватто. В античности считалось, что на острове Цитера (или Кифера) находится святилище богини любви Венеры (Афродиты). Стиль рококо вообще и картины Ватто в частности пользовались большой популярностью среди художников, принадлежавших к кругу журнала «Мир искусства» и таких поэтов Серебряного века, как Андрей Белый и Михаил Кузмин. Кроме того, в имении Студенки, где провел свое детство Иванов, стояли огромные вазы, расписанные сценками на темы «галантных празднеств» беззаботных прогулок любовных парочек на лоне природы, которые наслаждаются сладостной гармонией мира мечты, о чем сам поэт позже вспоминал: «ИВатто и Шотландия у меня из отцовского (вернее прадедовского) дома. $Я<$...> играл ребенком на ковре в комнате, где портрет моей прабабушки <..> висел между двух саженных ваз импер<аторского > фарфора, расписанного мотивами из отплытья на о. Цитеру» [1, с. 70]. Здесь же, в названии, заявлен мотив отплытия, с которым будут так или иначе сопрягаться, взаимодействовать и пересекаться все остальные поэтические мотивы сборника. Нельзя не согласиться с В. Коровиным, указавшего, что причиной обращения юного поэта к данному мотиву стало господствующее в начале XX века в среде русских модернистов настроение скуки, 
тоски, неудовлетворенности наличной действительностью [9, с. 588589], породившего в итоге романтическое устремление в сферу грез, утопии, прекрасной, но недостижимой идиллии и погружению в игровую поэтику прошлых эпох.

В эпиграфе, взятом из стихов Федора Сологуба, мотив отплытья дополняется мотивом пути:

Путь мой трудный, путь мой длинный, Я - один в стране пустынной,

Но услады есть в пути -

Улыбаюсь, забавляюсь,

Сам собою вдохновляюсь -

И не скучно мне идти.

Ф. Сологуб [8]

Фрагмент стихотворения Сологубаначинается с существительного «путь», которое трижды повторяется на небольшом пространстве текста, и завершается глаголом движения «идти». Таким образом, лирический герой предлагает читателю отправиться вместе с ним в поэтическое странствие, обещая, что трудности, ожидающие его впереди, сполна окупятся предвкушаемыми наслаждениями, которые поэту приносит творческое вдохновение. Он убежден, то это странствие станет его спасением от скуки, которая, вероятно, является причиной (или одной из причин), побудившей его бежать от реальной действительности в мир мечты.

Мотивом погружения в мир мечты, пастушеской идиллии, который так любили изображать на своих картинах художники эпохи рококо, проникнуто первое стихотворение цикла, озаглавленное «Мечтательный пастух». В нем обозначены некоторые пространственные координаты пути поэта: в небесах ему светит «нежности звезда», т.к. Венера, постепенно бледнеет Луна, которую в античности олицетворяла богиня Диана, - «когда Диана станет матовою» [8]). Важную роль в художественном мире поэта играет водная стихия - река, пруд, причем вода становится зеркалом, 
отражающим небеса, тем самым устанавливается связь двух миров, совершенно в духе символизма, - мира горнего и дольнего:

В пруды, платанами обраменные, Луна роняет янтари [8].

В сонете-послании, адресованном Игорю Северянину, изображен идиллический мир лирического героя, с упоением погруженного в таинственную жизнь природы:

Ночь надо мной струит златой экстаз,

Дрожит во мгле неверный лук Дианин...

Ах, мир ночной загадочен и странен,

И кажется, что твердь с землей слилась [8].

В этом мире становится возможным то, что обычно остается недоступным: в любовном порыве-экстазе сливаются в единое целое земля и небесная твердь. Ночная симфония сельской пасторали противопоставляется «гаму и звону кирас», т.е. какофонии городской жизни.

Первая часть книги стихов, озаглавленная «Любовное зеркало», открывается брызжущим радостью, весельем и проникнутым танцевальным ритмом четырехстопного хорея стихотворением «На острове Цитере». От переживаний тоски, печали, вызванных одиночеством и предчувствием приближения зимы поэт переходит в стихотворении «Ранняя весна» к изображению пробуждающейся природы. И даже измена возлюбленной кажется чем-то ненастоящим, не стоящим того, чтобы долго об этом грустить. Переполненный витальной энергией, лирический герой, быстро утешившись, отправляется навстречу новым любовным приключениям:

Зовут к забаве сладострастной

Меня наперсницы харит.

Что плакать о любви несчастной,

Когда огонь в крови горит! [8]

Праздничное настроение первой части сменяется тяжелыми и мрачными стихами цикла «Клавиши природы». Его лейтмотивом 
становится мотив падения, упоминавшийся мельком в прологе («луна роняет янтари») как метафора отражения лунного света в водной глади. Теперь же этот мотив набирает силу и приобретает трагические обертоны. Падает Икар, слишком близко поднявшийся к солнцу и наказанный за свою дерзость:

И я упал, как горний прах.

Я в тлен ушел - безумец тленный...

Я умирал... В моих ушах

Смеялось солнце, царь вселенной [8].

Падает раненная кем-то птица («Пица упала. Птица убита...» [8]), кровавая луна роняет луч и т.д. Восходящее движение сменяется движением, направленным вниз, к земле (солнце «землю ударило плашмя» [8]), оно связано с гибельным погружением в морскую пучину или, что, по сути, становится в данном контексте синонимичным - в небесную глубину («И утонет месяц красный, // Не осилив звездных пут» или «Луна упала в бездну ночи» [8]).

Мотив отплытия в «Клавишах природы» трансформируется, меняется его смысловое наполнение. Теперь он связан не с ожиданием любовных утех на острове Цитере, а с морскими бурями и кровавыми пиратскими набегами:

Кто отплыл ночью в море

С грузом золота и жемчугов

И стоит теперь на якоре

У пустынных берегов?

Это тот, кого несчастье

Помянуть три раза вряд.

Это Оле - властитель моря,

Это Оле - пират [8].

В третьем цикле, озаглавленном «Когда падают листья...», мотив падения звучит уже в самом названии. Он соотносится с увяданием природы, осенней порой, метафорически осмысленной как завершение жизненного пути. Приходу «злой» осени в царство 
гармонии и любви посвящено первое стихотворение цикла. В «Вечерних строфах» лирический герой продолжает идти «сквозь нежный сумрак», однако цель его пути неясна, возможно, он прислушается в конце концов к настойчиво повторяющемуся зову сада, который «Неотступно шепчет: «Усни»...» [8].

Внутреннее состояние лирического героя раскрывается в «Элегии». Он остался в одиночестве, среди увядающих цветов, запах которых отравляет все вокруг. Он испытывает чувство скуки, тоскует по ушедшему навсегда прошлому и приходит к осознанию того, что его мечтам, которые поэт сравнивает с «бесплодным трудом Сизифа», не суждено сбыться.

Мотив падения, сопровождающий осенние изменения в природе, символизирует также любовную тоску лирического героя, оплакивающего утрату возлюбленной («Нету со мною любимой. // Ax! не дождаться мне радостной встречи»), и его творческую усталость:

Осени пир к концу уж приходит,

Сердце тонет в печали.

Слабые струны, порвитесь!

Падай на камни, бессильная лира... [8]

Обращаясь в заключительном цикле к теме страстей Христовых, поэт как бы переводит любовные переживания в новый регистр:

$\mathrm{O}$, сердечный сладкий восторг!

Взор Господен исполнен боли...

О, Христос, ты кровь нынче пролил

И сердца из скорби исторг.

О, сердечный сладкий восторг! [8]

Результатом становится решение удалиться от мира, к которому приходит лирический герой во время своих странствий, и принятие им схимы монаха:

Ухожу в зоревые туманы я -

Иная участь близка [8]. 
Посути,геройпрощаетсясжизнью, отдавпредпочтениеинобытию, поэтому в эпилоге мотив ухода трансформируется в мотив отплытия к иному миру, над которым сияет «свет таинственной звезды», а конечная точка пути мыслится как «светлая гавань», «где все горит иным огнем» (см. подробнее анализ танатологических мотивов в творчестве русских символистов в монографии Л.В. Гармаш [5]).

Таким образом, уже первый лирический цикл Георгия Иванова, несмотря на юный возраст автора, несет отпечаток зрелости и поэтического мастерства. «Отплытье на о. Цитеру» представляет собой сложно организованное единство тем и мотивов, среди которых ведущее место принадлежит мотивам отплытия, падения и ухода, семантически тесно связанным друг с другом. Они являются теми поэтическими скрепами, которые устанавливают связи между отдельными стихотворениями и придают всему лирическому цикл целостность и завершенность. Разумеется, единство ивановскому циклу придают не только сквозные мотивы и заглавие. В дальнейшем предполагается рассмотреть в качестве средств циклизации временную и пространственную организацию «Отплытья на о. Цитеру», более подробно остановиться на анализе образа лирического героя и его ипостасей и т.д.

\section{Литература}

1. Georgij Ivanov / Irina Odojevceva. Briefe an Vladimir Markov 1955-1958. Mit Einleilung herausgegeben von Hans Rothe. Weimar; Wien, 1994.

2. Белый А. Стихотворения и поэмы. Москва; Ленинград, 1966.

3. Библиотека русской критики. Критика русского символизма. Москва, 2002.

4. Блок А. Собр. соч.: В 8 т. Москва-Ленинград, 1963. Т. 7.

5. Гармаш Л.В. Танатологические мотивы в прозе русских символистов: монография. Харьков: Изд-во ООО «Щедрая усадьба плюс», 2015. $312 \mathrm{c}$.

6. Жирмунский В. М. Творчество Анны Ахматовой. Ленинград: Наука, 1973.

7. Игнатьев И.В. (псевд. Ивей). Нижегородец. 14 января 1912 года, № 103. 
8. Иванов Г. Стихотворения. URL: http://www.lib.ru/RUSSLIT/IWANOWG/ stihi.txt_with-big-pictures.html

9. Коровин В. Г.В. Иванов. История русской литературы XX - начала XXI века: Учебник для вузов в 3-х частях с электронным приложением. Часть II: 1925-1990 годы. Сост. и науч. ред. проф. В.И. Коровин. Москва: Гуманитарный изд. центр ВЛАДОС, 2014. С. 584-793.

10. Краткая литературная энциклопедия: В 9 т. Т. 8. Флобер-Яшпал. Москва: Сов. энцикл., 1975.

11. Крейд В. Петербургский период Георгия Иванова. Tenafly, 1989.

\section{References}

1. Georgy Ivanov / Irina Odojevceva. Briefe an Vladimir Markov 1955-1958. Mit Einleilung herausgegeben von Hans Rothe. Weimar; Wien, 1994.

2. Bely A. Poems. Moscow; Leningad, 1966.

3. Library of Russian criticism. Criticism of Russian Symbolism. Moscow, 2002.

4. Blok A. Works: In 8 vols. Moscow- Leningad, 1963. Vol. 7.

5. Garmash, L.V. Tanatologicheskie motivyi v proze russkih simvolistov [Tana-

6. tological motifs in prose of Russian symbolists]. Kharkiv: Schedraya usadba

7. plyus, 2015.312 p.

8. Zhirmunsky V. M. Creativity of Anna Akhmatova. Leningad: Nauka, 1973.

9. Ignatiev I.V. (pseudo. Ivey). Nizhny Novgorod. January 14, 1912, No. 103.

10. Ivanov G. Poems. URL: http://www.lib.ru/RUSSLIT/IWANOWG/ stihi. txt_with-big-pictures.html

11. Korovin V. G. Ivanov. The history of Russian literature of the XX - beginning of the XXI century: Textbook for universities in 3 parts with an electronic application. Part II: 1925-1990. Comp. and scientific. ed. prof. Korovin. Moscow: Humanitarian ed. VLADOS Center, 2014.P. 584-793.

12. Brief literary encyclopedia: In 9 vol. Vol. 8. Flaubert-Yashpal. Moscow: Sov. Encycl., 1975.

13. Kreid V. Petersburg period of Georgy Ivanov. Tenafly, 1989. 


\section{Анотація \\ С.Л. Лобзова. Рання творчість Георгія Іванова: ліричний цикл «Відплиття на о. Цитеру»}

Стаття присвячена аналізу першої поетичної збірки відомого російського поета Георгія Іванова «Відплиття на о. Цитеру» з точки зору прийомів ліричної циклізації. Це обумовлено, по-перше, недостатньою вивченістю ранньої творчості поета, а по-друге, спробою простежити способи мотивної організації іванівської книги і виділити неявні прийоми, які поет використовує в якості структурних поєднуючи елементів, що дозволяють об'єднати окремі вірші, до того ж написані в різних жанрах сонета, триолета, романса тощо, в поетичне ціле, створивши розгорнуту ліричну оповідь.

У результаті узагальнення наявного на сьогоднішній день теоретичного матеріалу були позначені основні циклостворюючі ознаки: наявність у циклу віршів заголовки, спільність хронотопу і ліричних героїв, можливість виділити єдиний ліричний сюжет, наскрізні образи, різні переклички між віршами на мовному та тематичному рівнях тощо.

На підставі аналізу тексту був зроблений висновок, що вже перший ліричний цикл Георгія Іванова, незважаючи на юний вік автора, несе відбиток зрілості й поетичної майстерності. «Відплиття на о. Цитеру» $\epsilon$ складно організованою єдністю тем і мотивів, серед яких провідне місце належить мотивами відплиття, падіння та від'їду, семантично тісно пов'язаним один з одним. Вони є тими поетичними засобами, які об'єднують окремі вірші та надають усьому ліричному циклові цілісність і завершеність. Зрозуміло, єдність іванівському циклу надають не тільки наскрізні мотиви і спільна назва. Надалі передбачається розглянути в якості засобів циклізації часову і просторову організацію «Відплиття на о. Цитеру», більш детально зупинитися на аналізі образу ліричного героя i його іпостасей тощо.

На думку автора статті, докладне вивчення цих прийомів дасть можливість читачеві не тільки краще зрозуміти задум Георгія Іванова, але також розширить уявлення про ліричний цикл як однин 3 найбільш поширених метажанрів Срібного століття. 
130 Наукові записки ХНПУ ім. Г.С. Сковороди. Літературознавство, 2019, вип. 4(94)

\section{Аннотация \\ С.Л. Лобзова. Раннее творчество Георгия Иванова: лирический цикл «Отплытье на о. Цитеру»}

Статья посвящена анализу первого поэтического сборника известного русского поэта Георгия Иванова «Отплытье на о. Цитеру» с точки зрения приемов лирической циклизации. Это обусловлено, во-первых, мало изученностью раннего творчества поэта, а во-вторых, попыткой проследить способы мотивной организации ивановской книги и неявные приемы, которые поэт использует в качестве структурных «скреп», позволяющих объединить отдельные стихи, к тому же написанные в разных жанрах сонета, триолета, романса и др., в поэтическое целое, создав развернутое лирическое повествование.

В результате обобщения имеющегося на сегодняшний день теоретического материала были обозначены основные циклообразующие признаки: наличие у цикла стихотворений заглавия, общность хронотопа и лирических героев, возможность выделить единый лирический сюжет, сквозные образы, различные переклички между стихотворениями на языковом и тематическом уровнях и т.д.

На основании анализа текста был сделан вывод, что уже первый лирический цикл Георгия Иванова, несмотря на юны возраст автора, несет отпечаток зрелости и поэтического мастерства. «Отплытье на о. Цитеру» представляет собой сложно организованное единство тем и мотивов, среди которых ведущее место принадлежит мотивам отплытия, падения и ухода, семантически тесно связанные друг с другом. Они являются теми поэтическими скрепами, которые связывают отдельные стихотворения и придают всему лирическому цикл целостность и завершенность. Разумеется, единство ивановскому циклу придают не только сквозные мотивы и заглавие. В дальнейшем предполагается рассмотреть в качестве средств циклизации временную и пространственную организацию «Отплытья на о. Цитеру», более подробно остановиться на анализе образа лирического героя и его ипостасей и т.д.

По мнению автора статьи, подробное изучение этих приемов даст возможность читателю не только лучше понять замысел Георгия Иванова, но также расширит представление о лирическом цикле как одном из самых распространенных метажанров Серебряного века. 


\section{Summary \\ S.L. Lobzova. The Early Work of George Ivanov: \\ Lyric Cycle "Sailing off to the Island of Citera"}

The article is devoted to the analysis of the first poetry collection of the famous Russian poet Georgy Ivanov "Sailing off to the island of Citera" in terms of lyrical cyclization techniques. This is due, firstly, to the little knowledge of the poet's early work, and secondly, to an attempt to trace the methods of motivational organization of the Ivanov's book and the implicit techniques that the poet uses as structural "scrapbooks" to combine individual poems, besides written in different genres - sonnet, triolet, romance, etc., into a poetic whole, creating a detailed lyrical narrative.

As a result of the generalization of the theoretical material available today, the main cyclic-forming features were identified: the presence of the title of the poem cycle, the commonness of the chronotope and lyrical heroes, the ability to create a single lyrical plot, cross-cutting images, various echoes between poems at the linguistic and thematic levels, etc.

Based on the analysis of the text, it was concluded that the first lyrical cycle of Georgy Ivanov, despite the young age of the author, bears the imprint of maturity and poetic mastery. "Sailing off to the island of Citera" is a complexly organized unity of themes and motifs, among which the leading place belongs to the motifs of sailing, falling and leaving, semantically closely related to each other. They are those poetic bonds that connect individual poems and give the whole lyrical cycle integrity and completeness. Of course, not only cross-cutting motifs and its title give unity to the Ivanov's cycle. In the future, it is supposed to consider the temporal and spatial organization "Sailing off to the island of Citera" to dwell in more detail on the analysis of the image of the lyrical hero and his hypostases, etc.

According to the author of the article, a detailed study of these techniques will enable the reader not only to better understand the poetical plan of Georgy Ivanov, but also expand the idea of the lyrical cycle as one of the most common meta-genres of the Silver Age.

\section{Інформація про автора}

Лобзова Світлана Леонідівна - кандидат філологічних наук, доцент кафедри практики англійського усного і писемного мовлення Харківського 
132 Наукові записки ХНПУ ім. Г.С. Сковороди. Літературознавство, 2019, вип. 4(94)

національного педагогічного університету ім. Г.С. Сковороди; вул. Валентинівська, 2, м. Харків, 61168, Україна; e-mail: sl.konfeta@gmail.com; http://orcid.org/0000-0002-8050-7519 